\title{
Patterns of use of flexible sigmoidoscopy, colonoscopy and gastroscopy: A population-based study in a Canadian province
}

Robert J Hilsden MD PhD FRCPC

RJ Hilsden. Patterns of use of flexible sigmoidoscopy, colonoscopy and gastroscopy: A population-based study in a Canadian province. Can J Gastroenterol 2004;18(4):213-219.

BACKGROUND \& AIMS: Flexible sigmoidoscopy, colonoscopy and gastroscopy are important in the diagnosis and treatment of gastrointestinal (GI) diseases. Pressure on endoscopy resources is expected due to increased screening for GI cancers. The present study examined patterns of use of GI endoscopy in a Canadian province, Alberta, with universal health care insurance.

METHODS: Data on physician payments from January 1, 1994 to March 31, 2002 were used to calculate age-sex adjusted rates and patterns of use.

RESULTS: The gastroscopy rate increased by $17 \%$, from 9.7 (95\% CI 9.6 to 9.9 ) to 10.3 (95\% CI 10.1 to 10.5$)$. The colonoscopy rate increased by $105 \%$, from 4.8 ( $95 \%$ CI 4.6 to 5.0 ) to 9.8 (95\% CI 9.6 to 10.1 ). Flexible sigmoidoscopy rates declined by $10 \%$, from 4.68 ( $95 \%$ CI 4.56 to 4.80 ) to 4.21 ( $95 \%$ CI 4.11 to 4.32 ). The increase in colonoscopy rates occurred in all age groups, whereas gastroscopy rates increased only in the older age groups. Regional variation in procedure rates was evident, but rural health regions did not have consistently lower rates than the large urban regions. A polypectomy was performed on $23.7 \%$ of male patients and $15.4 \%$ of female patients at time of colonoscopy. Rates of polypectomy for individual endoscopists ranged from $0 \%$ to $60 \%$.

CONCLUSIONS: There has been a marked increase in gastroscopy and colonoscopy rates, likely due to a broadening of indications rather than just increased use for cancer screening. Modest regional variation in rates exists, but there is no direct evidence of limited rural access to endoscopy. Reasonable polypectomy rates were seen but important variations between endoscopists exist.

Key Words: Gastrointestinal endoscopy; Physician's practice patterns; Small-area analysis

\section{Sigmoïdoscopie, coloscopie et gastroscopie souples : étude menée en population, dans une province, au Canada, sur les pratiques d'utili- sation}

CONTEXTE : La sigmoïdoscopie, la coloscopie et la gastroscopie souples jouent un rôle important dans le diagnostic et le traitement des maladies digestives. Une pression accrue sur les ressources en endoscopie est à prévoir en raison de l'augmentation de la demande pour la détection des cancers. La présente étude a porté sur l'utilisation de l'endoscopie digestive en Alberta, province canadienne dotée d'un régime universel d'assurance-maladie.

MÉTHODE : Des données sur les honoraires versés aux médecins entre le $1^{\text {er }}$ janvier 1994 et le 31 mars 2002 ont servi à calculer les taux ajustés selon l'âge et le sexe, et les pratiques d'utilisation.

RÉSULTATS : Le taux de gastroscopie a augmenté de $17 \%$; il est passé de $9,7 \%$ (intervalle de confiance [IC] à $95 \%: 9,6-9,9)$ à 10,3\% (IC à $95 \%: 10,1-10,5)$. Celui de la coloscopie a augmenté de $105 \%$; il est passé de $4,8 \%$ (IC à $95 \%$ : 4,6-5,0) à 9,8 \% (IC à $95 \%$ : 9,6-10,1). Par contre, celui de la sigmoïdoscopie souple a diminué de $10 \%$; il est passé de $4,68 \%$ (IC à $95 \%: 4,56-4,80$ ) à 4,21 \% (IC à $95 \%: 4,11-4,32$ ). L'augmentation du taux de coloscopie a été constatée dans tous les groupes d'âge, tandis que l'augmentation du taux de gastroscopie n'a été observée que dans les groupes d'âge avancé. Nous avons également noté des variations régionales des taux d'utilisation, mais les régions sanitaires rurales n'enregistraient pas toujours les taux plus faibles par rapport aux régions sanitaires urbaines. Une polypectomie a été pratiquée chez 23,7\% des hommes comparativement à 15,4\% des femmes au moment de la coloscopie. Les taux de polypectomie entre les endoscopistes variaient de 0 à $60 \%$.

CONCLUSIONS : Les taux de gastroscopie et de coloscopie ont connu une forte augmentation, probablement due à un élargissement des indications plutôt qu'à une simple augmentation de la demande pour la détection du cancer. Il existe certes de faibles variations régionales, mais rien n'indique à première vue que l'accès à l'endoscopie soit limité dans les régions rurales. Des taux raisonnables de polypectomie ont été relevés, mais il existe des écarts importants entre les endoscopistes.
Wh hen health care resources are limited, the understanding of how medical procedures are used in a population is important to identify potential inequities or inefficiencies and to plan for future needs. Since the advent of flexible endoscopes in the late 1960s, endoscopy of the upper and lower gastrointestinal (GI) tract has assumed a critical role in the diagnosis and treatment of disorders of the esophagus, stomach, duodenum, terminal ileum and colon. The most commonly performed endoscopic procedures of the GI tract are flexible sigmoidoscopy, colonoscopy and esophagogastroduodenoscopy. Changing patterns of use $(1,2)$, especially for screening for malignant or premalignant lesions, has the

Department of Medicine, University of Calgary, Calgary, Alberta

Correspondence: Dr Robert Hilsden, Department of Medicine, 3330 Hospital Drive Northwest, University of Calgary, Calgary, Alberta

T2N 4N1. Telephone 403-210-9355, fax 403-220-8747, e-mail rhilsden@ucalgary.ca

Received for publication October 23, 2003. Accepted February 13, 2004 


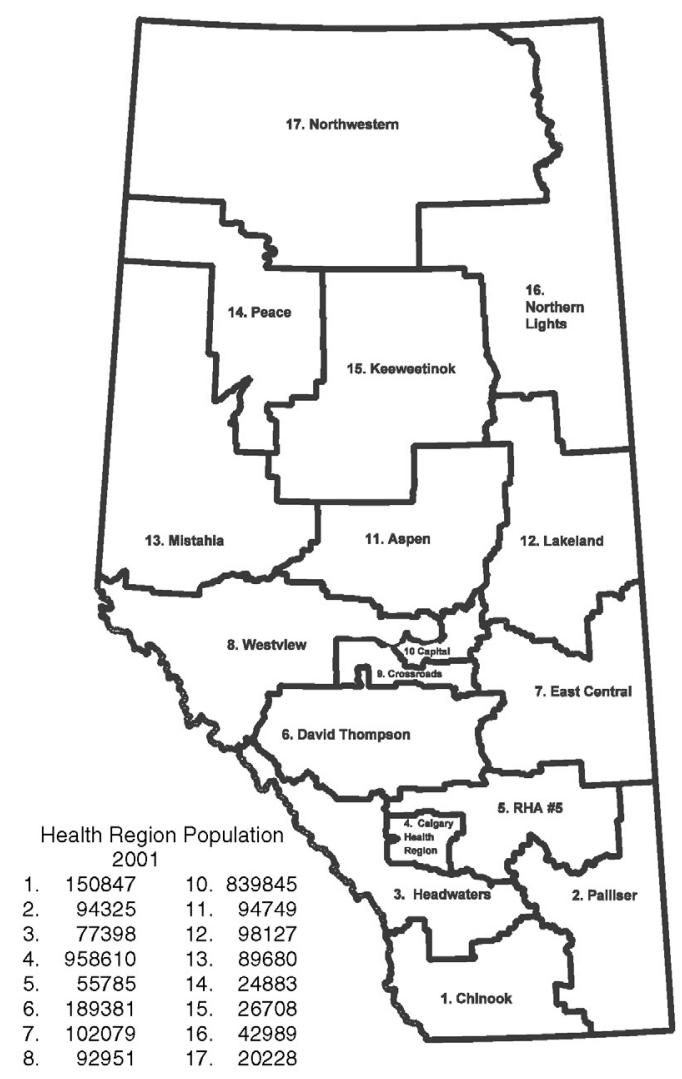

Figure 1) 2001 Alberta health region boundaries

potential to put an increasing burden on endoscopy resources at a regional, provincial and even national level. Although there is a general impression of increasing endoscopy rates, this has not been defined in a Canadian setting. Gastroscopy rates increased by $128 \%$ from 1988 to 1998 in Australia (3). The use of endoscopy for cancer screening has the potential to markedly increase procedure rates, not only through the initial screening procedure but also through the need for ongoing surveillance in those with abnormal baseline studies.

Identifying regional variations in procedures rates may highlight possible inequities in health service delivery. Furthermore, regional variations can have consequences on the costs of the health care system, on the health of the population and on health care policies. Because endoscopy expertise is concentrated in specialists who are located primarily in larger urban areas, limited access to endoscopy by those residing in rural areas is a valid concern. Significant regional variation in gastroscopy rates was reported among Medicare beneficiaries in the United States in 1981 (4). However, the degree of variation was the sixth lowest among the 30 procedures examined. Variation in endoscopy rates was also noted in Quebec in 1994 (5). These two sets of data are now outdated.

To maximize the reduction of colorectal cancer in those undergoing flexible sigmoidoscopy and colonoscopy, adequate polyp detection rates are essential. A target of adenoma prevalence rates at the time of screening colonoscopy of $25 \%$ or higher in men 50 years of age or older and $15 \%$ or higher in women 50 years of age or older has been suggested (6).
Furthermore, appropriate timing of surveillance colonoscopy is required after a polypectomy to maximize future cancer prevention while minimizing cost and risk to the patient. Current recommendations are for follow-up colonoscopy three to five years following a polypectomy, depending on the number and size of polyps removed (7).

The purpose of the present study was to examine patterns of use of flexible sigmoidoscopy, colonoscopy and gastroscopy in a population-based sample. Specific objectives were to determine provincial procedure rates from 1994 to 2002; to determine if significant regional variations in procedure rates exist; to determine polyp prevalence rates and whether individual endoscopists polypectomy rates depend on their annual colonoscopy volume; and to determine patterns of colonoscopy use following a flexible sigmoidoscopy or a polypectomy.

To meet these objectives, the author examined endoscopy use in Alberta, Canada. In 2001, this Canadian province had a population of 3.06 million with two large urban centres (population greater than 750,000), several smaller cities and large, less populated rural and northern areas. Albertans, like all Canadians, receive health care through a publicly funded universal insurance program that covers costs of all medically necessary hospital and physician services. During the time of this study, health care was administered through 17 health regions (Figure 1). In 2001, the population of these regions ranged from just over 20,000 to nearly one million. Two regions (Regional Health Authorities 4 and 10) encompass primarily the two large cities, Calgary and Edmonton. The remaining health regions cover larger geographic areas that may include smaller cities, towns and rural areas. Regional variation could suggest limited access for rural residents if higher rates were noted in the health regions for the two large urban health regions (Calgary Health Region and Capital Health Region [Edmonton]).

\section{METHODS}

\section{Data sources}

Data from the Alberta Health Care Insurance Plan (AHCIP) on physician payments for endoscopy-related services were obtained from Alberta Health and Wellness, the provincial government department responsible for administering health care. Data elements included patients' date of birth, sex, postal code of residence at date of service, service date, procedure code, up to three diagnostic codes, facility code and service provider specialty. Annual population estimates for Alberta and each of Alberta's 17 health regions for 1994 to 2002 were obtained from Alberta Health and Wellness (8).

\section{Sample selection}

Patients were included in the sample if they had at least one record for a flexible sigmoidoscopy, colonoscopy or gastroscopy (Schedule of Medical Benefits Codes 1.24B, 1.22 and 1.14) from January 1, 1994 to March 31, 2002. Records were also obtained for these patients for any large intestine polypectomy (55.21A). Patients were excluded if their postal code of residence at the time of the procedure was missing or outside of Alberta.

\section{Analysis}

Direct age-sex standardized procedure rates were calculated using the 1991 Canadian population as the standard (9). Because endoscopy rates are expected to vary depending on the age, and possibly the sex, of individuals, differences in crude procedure 
TABLE 1

Annual age-sex adjusted endoscopy rates and $95 \% \mathrm{Cls}$

\begin{tabular}{lrrr}
\hline Year & \multicolumn{1}{c}{ Gastroscopy } & \multicolumn{1}{c}{ Colonoscopy } & \multicolumn{1}{c}{$\begin{array}{c}\text { Flexible } \\
\text { sigmoidoscopy }\end{array}$} \\
\hline 1994 & $9.73(9.56-9.91)$ & $5.03(4.91-5.16)$ & $4.68(4.56-4.80)$ \\
1995 & $10.15(9.98-10.32)$ & $5.36(5.24-5.49)$ & $4.52(4.40-4.63)$ \\
1996 & $10.7(10.52-10.87)$ & $5.88(5.74-6.01)$ & $4.61(4.49-4.73)$ \\
1997 & $10.68(10.50-10.85)$ & $6.2(6.07-6.34)$ & $4.71(4.59-4.82)$ \\
1998 & $10.7(10.52-10.87)$ & $6.6(6.46-6.73)$ & $4.75(4.64-4.87)$ \\
1999 & $10.79(10.62-10.96)$ & $7.46(7.32-7.60)$ & $4.94(4.82-5.06)$ \\
2000 & $11.18(11.01-11.36)$ & $8.78(8.63-8.93)$ & $4.85(4.74-4.97)$ \\
2001 & $11.43(11.26-11.61)$ & $10.3(10.14-10.47)$ & $4.21(4.11-4.32)$ \\
$2002^{*}$ & $10.55(10.39-10.71)$ & $10.82(10.65-10.98)$ & $3.68(3.58-3.78)$ \\
\hline
\end{tabular}

${ }^{*}$ Estimated based on first three months

rates between different populations could be due to true differences in procedure rates and/or differences in the sex and/or age distributions of each population. Direct age-sex standardized rates are derived by applying the age- and sex-specific rates observed in each population to a single standard population. For each population, a single summary rate is calculated that reflects the numbers of events that would have been expected if the populations being compared had identical distributions by age and sex. Therefore, the age-sex adjusted rate is not the same as the observed 'crude' rate. However, because the age and sex distribution of the Alberta population during the years included in this study is so similar to the 1991 Canadian population, the crude Alberta endoscopy rates per 1000 population are always very close to the age-sex adjusted rates. Rates for 2002 were estimated based on procedures performed until March 31, 2002. To estimate the 2002 rates, the number of procedures performed in the first three months was multiplied by four and then by a correction factor. The correction factor was required because the number of procedures performed in the first quarter of each preceding year differed slightly from the average performed in the subsequent three quarters. The correction factor was based on quarterly rates from 1999 to 2001. Fiveyear age groups were used except for children and younger adults ( 0 to 19 years and 20 to 34 years, respectively) and those older than 75 years to insure adequate numbers of procedures in each strata. Rates were calculated for the entire province and for each health region (2001 boundaries). To insure stable rates for the health region analysis, three-year average rates were calculated and three northern health regions (regions 14, 15 and 17) were grouped together. Each patient was assigned a health region of residence using a postal code to health region link created by Alberta Treasury. Bonferonni corrected 95\% CIs were calculated for each rate. To test the null hypothesis of equality of rates, the $\chi^{2}$ test described by Carriere and Roos was used (10). The advantage of this method is that it is robust to departures from parametric assumptions, such as extrabinomial variation and recurrence of events within the time period studied. It tests the null hypothesis that the rate for each strata (ie, health region) is equal to the standardized rate for all stratum combined. Correlation coefficients were used to measure the strength of the relationship between regional rates of the three procedures.

The proportion of patients aged 50 to 80 years undergoing a polypectomy at the time of a first recorded colonoscopy was determined. For each endoscopist performing at least 10 colonoscopies annually, the proportion of colonoscopies with a concomitant polypectomy was calculated and compared with the endoscopist's

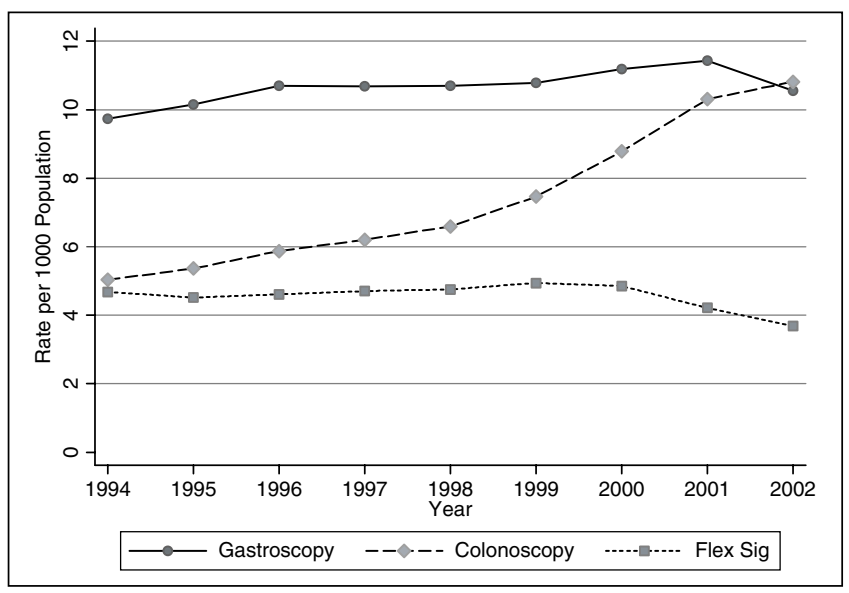

Figure 2) Provincial age-sex adjusted endoscopy rates, 1994 to 2002. There has been a marked increase in colonoscopy rates. The rates for gastroscopy increased somewhat between 1994 and 2001. Flexible sigmoidoscopy (Flex Sig) rates remained stable between 1994 and 2000, but have declined more recently. Rates for 2002 are estimated based on data from January to March 2002

experience, measured by the annual average number of colonoscopies performed by that endoscopist in patients of all age groups.

This study was approved by the Conjoint Health Research Ethics Board at the University of Calgary.

\section{Sample}

\section{RESULTS}

Records on 120,224 individuals who underwent 161,591 colonoscopies, 162,000 individuals who underwent 242,163 gastroscopies and 84,689 individuals who underwent 104,914 flexible sigmoidoscopies from January 1, 1994 to March 31, 2002 were provided by Alberta Health and Wellness. Postal code of residence was missing for $388(0.24 \%), 746(0.31 \%)$ and $398(0.38 \%)$ of those undergoing a colonoscopy, gastroscopy or flexible sigmoidoscopy, respectively. The postal code of residence at the date of the procedure was outside of Alberta for $200(0.12 \%), 258(0.11 \%)$ and $109(0.10 \%)$ of those undergoing a colonoscopy, gastroscopy and flexible sigmoidoscopy, respectively. Those with a missing or out-ofprovince postal code were excluded from further analysis.

\section{Provincial endoscopy rates}

From 1994 to 2001, the number of gastroscopies performed annually increased by $39 \%$, from 24,463 to 34,060 . The annual number of colonoscopies increased by $147 \%$, from 12,495 to 30,818 . The number of flexible sigmoidoscopies increased by $6 \%$, from 11,7565 to 12,541 . The annual provincial age-sex adjusted colonoscopy, flexible sigmoidoscopy and gastroscopy rates from 1994 to 2001 and estimated rates for 2002 are shown in Table 1 and Figure 2. Between 1994 and 2001, the annual age-sex adjusted rate increased $17 \%$ for gastroscopy and $105 \%$ for colonoscopy but decreased by $10 \%$ for flexible sigmoidoscopy.

Age-specific rates for men and women for each of the three endoscopic procedures are shown in Figure 3. The increase in colonoscopy rates was seen in all adult age groups. Overall, the age-adjusted colonoscopy rate was consistently higher in 


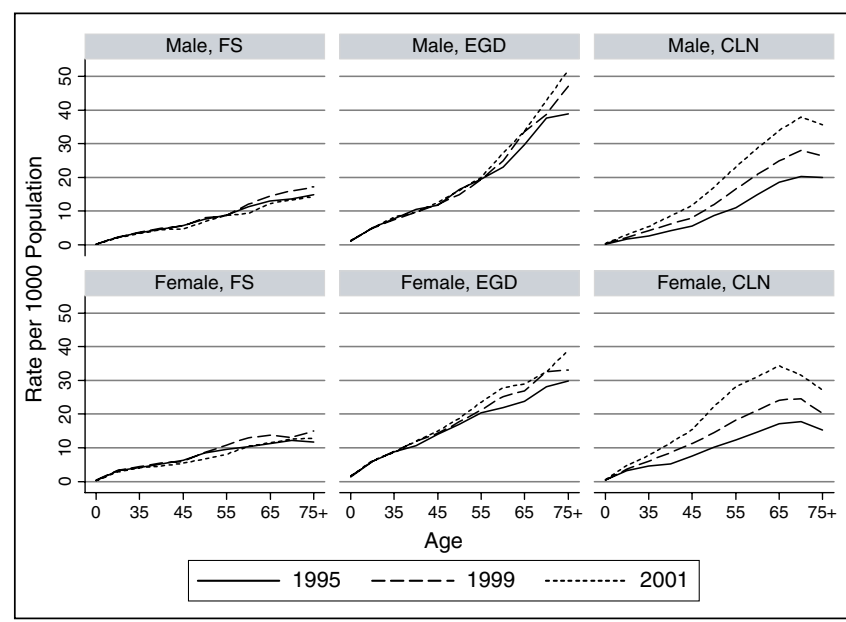

Figure 3) Age-specific rates for men and women for flexible sigmoidoscopy (FS), gastroscopy (EGD) and colonoscopy (CLN). Colonoscopy rates increased in all age groups between 1995 and 2001, whereas gastroscopy rates increased only in those over the age of 55 years

women than in men (Figure 4$)$. The age-adjusted colonoscopy rate per 1000 men increased from 4.8 (95\% CI 4.6 to 5.0 ) in 1994 to 9.8 (95\% CI 9.6 to 10.1 ) in 2001. Over the same period, the rates per 1000 women increased from 5.3 (95\% CI 5.1 to 5.5) to 10.9 (95\% CI 10.7 to 11.2 ).

The increase in gastroscopy rates was seen predominantly in the older age groups. For example, men in all age groups under the age of 65 years showed less than a 10\% increase between 1994 and 2001. In contrast, the rate increases for men in the 65 to 69,70 to 74 and 75 years and older age groups were $14.7 \%, 22.4 \%$ and 38.0\%, respectively. From 1994 to 2001, there was no significant difference between men and women in the age-adjusted gastroscopy rates. For example, in 2001, the age-adjusted gastroscopy rate was 11.6 (95\% CI 11.3 to 11.8$)$ for men and 11.5 (95\% CI 11.3 to 11.8 ) for women.

There was no appreciable change in the age-specific flexible sigmoidoscopy rates between 1995 and 2001. There was no statistically significant difference in the age-adjusted flexible sigmoidoscopy rates for men and women.

Colonoscopy rates were very low in those younger than 19 years of age, rose steadily until reaching a peak in the 65 to 75 year age group and then tapered off slightly (Figure 3). Before age 65 , women had higher age-specific rates than men, but after age 65 this pattern was reversed. Gastroscopy and flexible sigmoidoscopy rates continued to climb through life, peaking in the oldest age group, those over 74 years of age.

\section{Regional variations in endoscopy rates}

To examine regional variations in gastroscopy and colonoscopy rates, three-year average rates for 1994 to 1996 and 1999 to 2001 were calculated for each health region and the province as a whole. Figure 5 shows the 95\% CIs for the gastroscopy and colonoscopy rate for 1999 to 2001 for each health region. In each three-year time period, there were marked variations in regional rates that exceeded what would be expected by chance alone $(\mathrm{P}<0.0001$ for each period). There was a 3.3-fold difference between the highest and lowest regional gastroscopy rates in 1994 to 1996 and a 2.9-fold difference in 1999 to 2001. There was a 2.8-fold difference between the highest and lowest

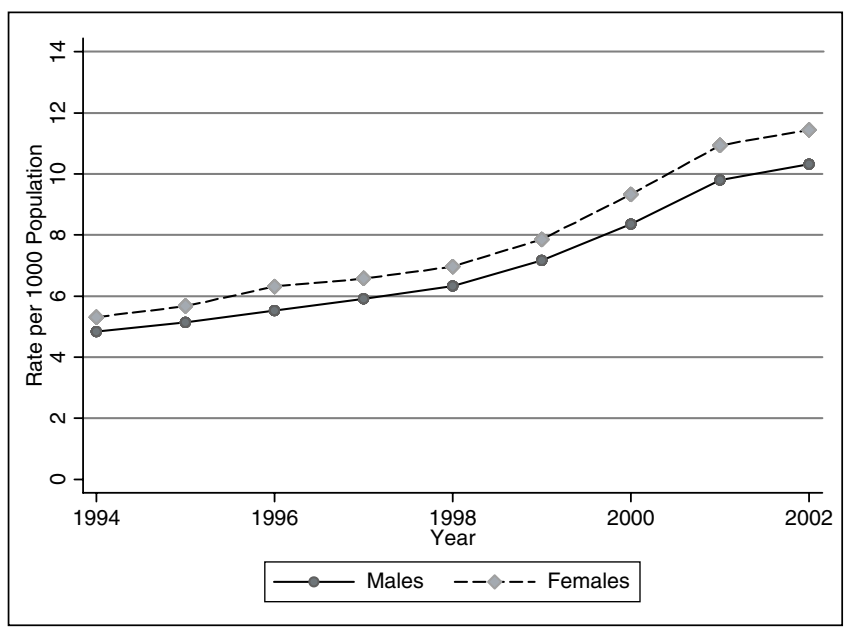

Figure 4) Age-adjusted colonoscopy rates for men and women. Women have a consistently higher colonoscopy rate than men. The rates for both groups have increased from 1994 to 2002

regional colonoscopy rate in 1994 to 1996 , but this fell to a twofold difference in 1999 to 2001 . There was only a weak correlation between health regions' colonoscopy and gastroscopy rates in either 1994 to 1996 (correlation coefficient: 0.46, $\mathrm{P}=0.08$ ) or 1997 to 2001 (correlation coefficient: 0.43, $\mathrm{P}=0.11$ ).

The ratio of the regions with the highest to lowest flexible sigmoidoscopy rate was 3.2 from 1994 to 1996 and 2.3 from 1999 to 2001 . There was a strong negative correlation between regional colonoscopy and flexible sigmoidoscopy rates from 1994 to 1996 (correlation coefficient: $-0.63, \mathrm{P}=0.011$ ) but less so in the later time period (correlation coefficient: -0.36 , $\mathrm{P}=0.19$ ).

\section{Colonoscopy following a flexible sigmoidoscopy}

There were 30,615 patients age 50 to 75 years who underwent a flexible sigmoidoscopy without having undergone a colonoscopy in the previous 12 months. Of these, 3608 (11.8\%) underwent a colonoscopy within six months of their sigmoidoscopy. A polypectomy was performed in 1286 (35.6\%) at the time of their colonoscopy. The likelihood that a patient underwent a colonoscopy within six months of a flexible sigmoidoscopy depended on their health region of residence. For example, for those who underwent their flexible sigmoidoscopy between 1999 and March 31, 2001, the probability across regions varied from $6.5 \%$ to $21.1 \%(\mathrm{P}<0.001)$. There was a strong correlation between the probability of patients residing within a given health region undergoing a colonoscopy following a sigmoidoscopy and the overall colonoscopy rate for that region (correlation coefficient: 0.64 , $\mathrm{P}=0.015)$, but this correlation was primarily due to a single outlying region with the highest colonoscopy rate and the highest proportion undergoing colonoscopy after sigmoidoscopy. If this region was excluded, the correlation was much weaker and no longer statistically significant (correlation coefficient: $0.22, \mathrm{P}=0.47$ ).

\section{Polypectomy}

There were 49,763 individuals age 50 to 80 years who underwent a colonoscopy from 1997 to 2001 without having 


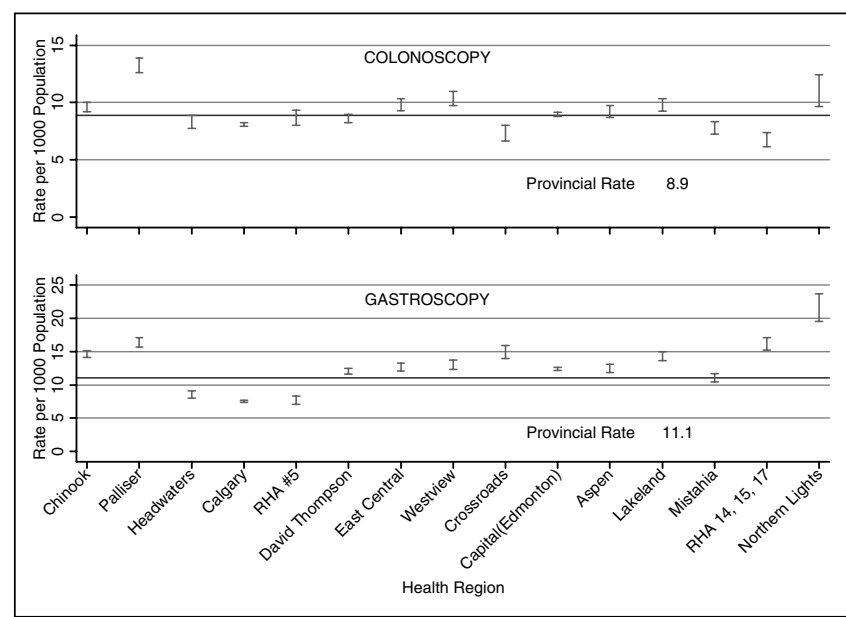

Figure 5) Age-sex adjusted colonoscopy and gastroscopy rates for Alberta health regions, 1999 to 2001. 95\% CIs are shown for each region's rates. The horizontal bar is the provincial rate. Significant regional variation exists for both gastroscopy and colonoscopy. Urban regions (Calgary and Capital) do not have consistently higher rates than more rural areas

undergone a colonoscopy within the preceding 36 months. A concomitant polypectomy was performed on 9780 (19.2\%). Males were more likely to undergo a polypectomy than females ( $23.7 \%$ versus $15.4 \%, 95 \%$ CI for the difference 7.7 to 9.1 , $\mathrm{P}<0.0001)$. When considering procedures performed by individual endoscopists in these patients, marked variation in the proportion of colonoscopies performed by each endoscopist with a concomitant polypectomy was noted ranging from a low of $0 \%$ to a high of $60 \%$. Figure 6 shows for each endoscopist, the proportion of colonoscopies with polypectomy by the average number of colonoscopies (patients of all ages) performed annually by the endoscopist.

There were 9024 individuals aged over 30 years who underwent a first polypectomy between 1994 and 1998. A second colonoscopy was performed on 4885 (54.1\%). The median time to the second colonoscopy was 26 months. Twenty-five per cent of those who underwent a repeat colonoscopy did so within 13 months of their first colonoscopy. A polypectomy was performed at the time of the second colonoscopy in 1581 (32.5\%).

\section{DISCUSSION}

The Alberta population registered with AHCIP increased by $11 \%$ from 1994 to 2001. Over the same time period, the number of gastroscopies and colonoscopies increased by $39 \%$ and $147 \%$, respectively. Flexible sigmoidoscopy numbers decreased by $6 \%$. For gastroscopies, increased rates of use were confined to the older age groups, whereas increases in colonoscopy rates were seen in all age groups. These patterns do not suggest that increased utilization was solely due to increased use for screening purposes. If that were the case for colonoscopy, one would have expected a disproportionate increase in colonoscopy rates in those over the age of 50 years, the starting age at which screening is commonly recommended to begin $(7,11)$. However, the effect of screening should not be underestimated. At my own institution in 2001, approximately $20 \%$ of all colonoscopies were performed for screening purposes (unpublished data). Colon cancer screening is likely to place increasing

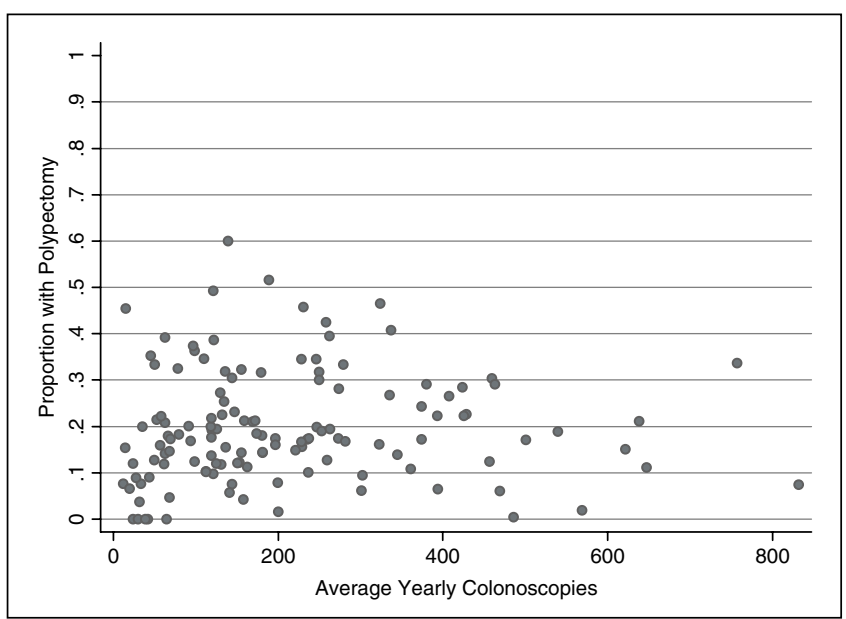

Figure 6) Endoscopists' polypectomy rate by annual case volume. The proportion of colonoscopies on patients age 50 to 80 years with an associated polypectomy varies widely among endoscopists. In general, greater variation is seen among endoscopists with lower annual case volumes

demands on colonoscopy services for the foreseeable future. Public awareness of colorectal cancer has been increased by celebrities and media campaigns and has resulted in increased colonoscopy performance in the United States (12), The American Consortium guidelines recommend screening all people for colorectal cancer using fecal occult blood testing (FOBT), flexible sigmoidoscopy, air-contrast barium enema or colonoscopy (13). The more conservative Canadian Task Force for the Preventative Health Exam guidelines support the use of FOBT or flexible sigmoidoscopy (11). Experts often advocate for the use of colonscopy even in those at average risk for colorectal cancer (14). Colonoscopy is the preferred diagnostic test following a positive FOBT. With positivity rates of up to $4.4 \%$ in the published clinical trials (15), a populationbased FOBT screening program would generate a large number of colonoscopies. Therefore, regardless of the primary screening tool used, a program to increase colorectal cancer screening will dramatically increase the number of colonoscopies performed. Concerns have already been raised by the Canadian gastroenterology community as to the potential impact on endoscopy resources of widespread colorectal cancer screening (16).

Despite the increased emphasis on colorectal cancer screening, there has been no appreciable increase in flexible sigmoidoscopy rates. It is uncommon for Canadian family physicians to perform flexible sigmoidoscopy (17). Therefore, most physicians who perform flexible sigmoidoscopy also perform colonoscopy. Physicians who perform both procedures may preferentially use colonoscopy for screening of asymptomatic people and the diagnostic evaluation of symptomatic ones, a practice that could have been driven by both clinical trial evidence and expert opinion (14,18-20). In fact, one might have expected a much more significant and consistent decrease in flexible sigmoidoscopy rates coinciding with the increase in colonoscopy rates. The flat flexible sigmoidoscopy rates throughout the 1990s suggest that the increase in colonoscopy rates were not due to physicians using colonoscopy instead of flexible sigmoidoscopy. A possible 
decline in flexible sigmoidoscopy rates was only seen in 2001 and the estimated rate for 2002. Endoscopy resources may have been maximized by the increase in colonoscopy rates in the late 1990s requiring physicians to shift existing endoscopy resources away from flexible sigmoidoscopy towards colonoscopy to continue the expansion of colonoscopy.

Increases in gastroscopy and colonoscopy rates are also likely due to a broadening of indications. Whether any of the increase is due to procedures performed for inappropriate indications cannot be determined with this data. Previous attempts have been made to explain geographic variations in endoscopy rates by examining the proportion of procedures deemed inappropriate based on expert consensus (1). Classifying procedures as appropriate or inappropriate is problematic because the classification scheme may quickly become out of date. For example, Chassin et al (21) of the Rand Corporation rated indications for upper GI tract endoscopy as appropriate, equivocal or inappropriate based on a consensus of experts. The most frequent inappropriate indication in a study of patients from the United States was "patient has dysphagia with normal immune system; neither manometry nor upper GI tract roentgenogram performed" (21). However, there has been growing recognition of the superiority of gastroscopy for the evaluation of upper GI symptoms, both in terms of diagnostic accuracy and patient acceptance $(22,23)$. This is reflected in a Canadian study that demonstrated that endoscopists classified many procedures as appropriate that were classified as equivocal or inappropriate by Chassin et al (21), including the one described above (24). The authors felt the differences between the Rand and Canadian endoscopists' ratings were due to concerns about missing malignancies and a lack of confidence in barium studies. Thus, the indications for endoscopy have clearly broadened in Canada and elsewhere, with endoscopy being used earlier in the diagnostic process and frequently supplanting other diagnostic modalities, especially contrast radiology.

The financial benefits of performing more procedures has also been suggested as a driver of increasing procedure rates (25). However, if this were the primary driver, one would have expected relatively similar increases in both gastroscopy and colonoscopy rates. In June 2000, there was only a 30\% difference in the physician fees paid for these two procedures. Furthermore, a typical gastroscopy takes less time to perform then a colonoscopy.

Therefore, the modest increase in gastroscopy rates and the marked increase in colonoscopy rates are likely due to several factors, including a broadening of indications, a greater availability of endoscopy services and greater acceptance of endoscopy as an initial diagnostic test over barium studies.

Modest regional variation in procedures rates was noted. However, there was no evidence that rates were highest in regions encompassing large urban centers. In fact, the Calgary Health Region was consistently below the provincial average for both colonoscopy and gastroscopy. Therefore, residents of more rural areas appear to have appropriate access to GI endoscopy. A study of regional endoscopy patterns in Quebec in 1994 published only in abstract form also concluded that there was no evidence that remote regions were underserved (5).

Adequate access to colonoscopy is critical for the successful implementation of colorectal cancer screening, regardless of the primary screening test used. Local access to colonoscopy for either initial screening or appropriate diagnostic follow-up following FOBT will be critical to minimize costs, increase patient acceptance and prevent overwhelming endoscopy resources in larger centers.

Regional variation in procedure rates is a widely appreciated phenomenon, but a ready explanation for these variations, or even the ability to define the right rate, remains elusive. In most instances, attempts to link procedure rates to the health care needs of the population have been unsuccessful $(26,27)$. The important finding in this study is that rural areas do not appear to be disadvantaged. Whether some regional rates are too low and others are too high or all rates are too low or all rates are too high is beyond the scope of this study and the answer may depend more on one's philosophy on the use of endoscopy, especially as a primary screening modality, rather than scientific evidence. Validation of endoscopists' increased performance of colonoscopy may require future documentation of decreased incidence and mortality rates of colorectal cancer. Similarly examining regional trends in colorectal cancer incidence and mortality may provide insights into whether regional variation in colonoscopy rates are significantly affecting the health of the population.

Cost effective colorectal cancer screening also requires appropriate rates of polypectomy and colonoscopy intervals. Recent continuous quality assurance guidelines have suggested that adenoma detection rates of $25 \%$ for men and $15 \%$ for women should be achieved (6). In Alberta, 23.7\% of men and $15.4 \%$ of women aged 50 to 80 years undergoing their first observed colonoscopy underwent a polypectomy. The fact that a polypectomy was performed does not indicate that the removed polyp was an adenoma. Furthermore, the majority of these procedures would have not been performed for screening. However, the observed polypectomy rates are reassuring. Unfortunately, marked variation in polypectomy rates were seen between individual endoscopists ranging from $0 \%$ to $60 \%$. This is clearly concerning and suggests that some patients may not be achieving a benefit from their colonoscopy.

Guidelines currently recommend a three or five year interval for most patients following polypectomy. In Alberta, 50\% of patients who underwent a subsequent colonoscopy following a polypectomy did so within 26 months of their initial colonoscopy. This suggests that resources are being used for overly intensive surveillance that may be better used elsewhere, such as primary screening.

The use of administrative databases in this study for providing population-based data is associated with several limitations. First, accurate indication and diagnosis information is not available from the AHCIP database. Because physicians are remunerated based on their billings, it is expected that the reporting of endoscopic procedures is high. Over the years examined, the billing codes for these procedures remained constant. However, some misclassification of procedures may occur by physicians billing colonoscopies as flexible sigmoidoscopies and vice versa.

\section{CONCLUSION}

There has been a marked increase in gastroscopy and colonoscopy rates from 1994 to 2002. The more than doubling in the colonoscopy rate cannot clearly be attributed to screening for colorectal cancer because increases were seen in all age groups. Modest regional variation in procedure rates exists, but there is no direct evidence of limited rural access to endoscopy. 
Appropriate polypectomy rates were seen, but important variation between the polypectomy rates of individual endoscopists exists.

FUNDING: Funding for this study was provided by the Alberta Heritage Foundation for Medical Research.

\section{REFERENCES}

1. Kahn KL, Kosecoff J, Chassin MR, Solomon DH, Brook RH. The use and misuse of upper gastrointestinal endoscopy. Ann Intern Med 1988;109:664-70.

2. Lieberman DA, De Garmo PL, Fleischer DE, Eisen GM, Helfand M. Patterns of endoscopy use in the United States. Gastroenterology 2000;118:619-24.

3. Westbrook JI. Trends in the utilization of diagnostic upper GI endoscopy in New South Wales, Australia, 1988 to 1998.

Gastrointest Endosc 2002;55:847-53.

4. Chassin MR, Brook RH, Park RE. Variations in the use of medical and surgical services by the Medicare population. N Engl J Med 1986;314:285-90.

5. Jobin $\mathrm{G}$, Blais R. Variations in the rate of use of gastrointestinal endoscopy in Quebec. Can J Gastroenterol 2000;14(Suppl A):49A. (Abst)

6. Rex DK, Bond JH, Winawer S, et al. Quality in the technical performance of colonoscopy and the continuous quality improvement process for colonoscopy: Recommendations of the US Multi-Society Task Force on Colorectal Cancer. Am J Gastroenterol 2002;97:1296-308.

7. Winawer S, Fletcher R, Rex D, et al. Colorectal cancer screening and surveillance: Clinical guidelines and rationale - Update based on new evidence. Gastroenterology 2003;124:544-60.

8. Alberta Health \& Wellness. Information to support health authority business plan and annual report requirements, 2002. $<$ www.health.gov.ab.ca/system/rhas/require/list.htm> (Version current at February 24, 2004).

9. Rothman KJ, Greenland S. Modern Epidemiology, 2nd edn. Philadelphia, Pennsylvania: Lippincott-Raven, 1998.

10. Carriere KC, Roos LL. Comparing standarized rates of events. Am J Epidemiol 1994;140:472-82.

11. Canadian Task Force on Preventive Health Care. Colorectal cancer screening. Recommendation statement from the Canadian Task Force on Preventive Health Care. CMAJ 2001;165:206-8.
12. Cram P, Fendrick AM, Inadomi J, Cowen ME, Carpenter D, Vijan S. The impact of a celebrity promotional campaign on the use of colon cancer screening - The Katie Couric effect. Arch Intern Med 2003;163:1601-5.

13. Winawer SJ, Fletcher RH, Miller L, et al. Colorectal cancer screening: Clinical guidelines and rationale. Gastroenterology 1997;112:594-642.

14. Podolsky DK. Going the distance-the case for true colorectalcancer screening. N Engl J Med 2000;343:207-8.

15. Ransohoff DF, Lang CA. Screening for colorectal cancer with the fecal occult blood test: a background paper. American College of Physicians. Ann Intern Med 1997;126:811-22.

16. Leddin D. The Canadian Association of Gastroenterology position on colon cancer screening. Can J Gastroenterol 2003;17:133.

17. Glaser SR. Utilization of sigmoidoscopy by family physicians in Canada. CMAJ 1994;150:367-71.

18. Rex DK, Mark D, Clarke B, Lappas JC, Lehman GA. Flexible sigmoidoscopy plus air-contrast barium enema versus colonoscopy for evaluation of symptomatic patients without evidence of bleeding. Gastrointest Endosc 1995;42:132-8.

19. Rex DK. Sigmoidoscopy or colonoscopy: Which way are we headed? Am J Gastroenterol 2000;95:1116-8.

20. Fine KD, Nelson AC, Ellington RT, Mossburg A. Comparison of the color of fecal blood with the anatomical location of gastrointestinal bleeding lesions: Potential misdiagnosis using only flexible sigmoidoscopy for bright red blood per rectum. Am J Gastroenterol 1999;94:3202-10.

21. Chassin MR, Kosecoff J, Park RE, et al. Does inappropriate use explain geographic variations in the use of health care services? A study of three procedures. JAMA 1987;258:2533-7.

22. Colin-Jones DG. Endoscopy or radiology for upper gastrointestinal symptoms? Lancet 1986;1:1022-3.

23. Stevenson GW, Norman G, Frost R, Somers S. Barium meal or endoscopy? A prospective randomized study of patient preference and physician decision making. Clin Radiol 1991;44:317-21.

24. Sutherland LR, Verhoef MJ, Meddings JB, et al. Endoscopists' opinions of indications for upper gastrointestinal endoscopy. Can J Gastroenterol 1997;11:221-7.

25. Levine MS, Laufer I. The upper gastrointestinal series at a crossroads. AJR Am J Roentgenol 1993;161:1131-7.

26. Frohlich N, Roos NP. Searching for El Dorado: The impossibility of finding the right rate. CMAJ 2002;167:880-1.

27. Roos NP, Roos LL Jr. Surgical rate variations: Do they reflect the health or socioeconomic characteristics of the population? Med Care 1982;20:945-58. 


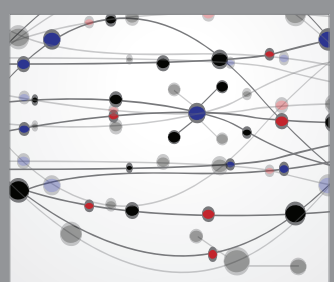

The Scientific World Journal
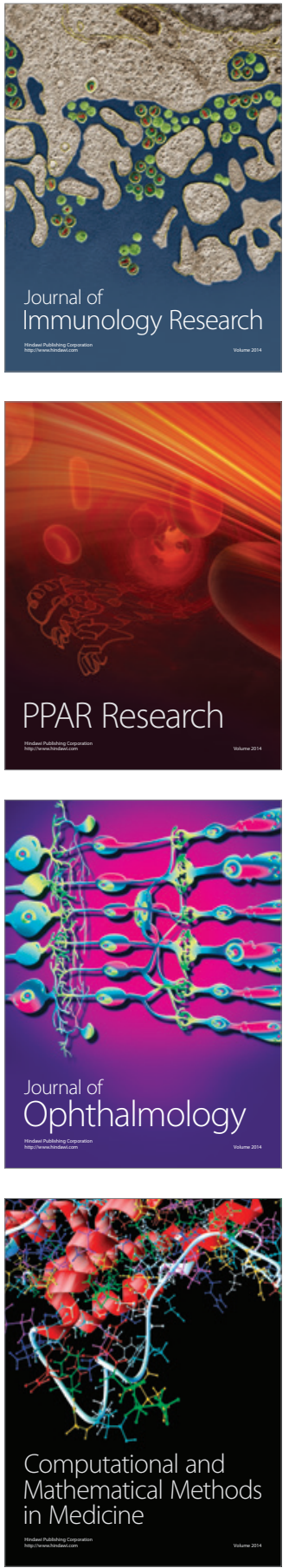

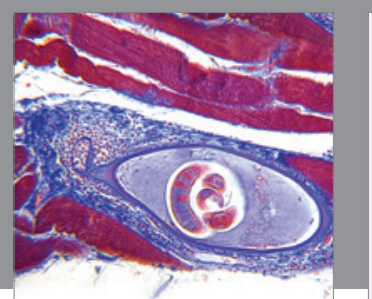

Gastroenterology Research and Practice

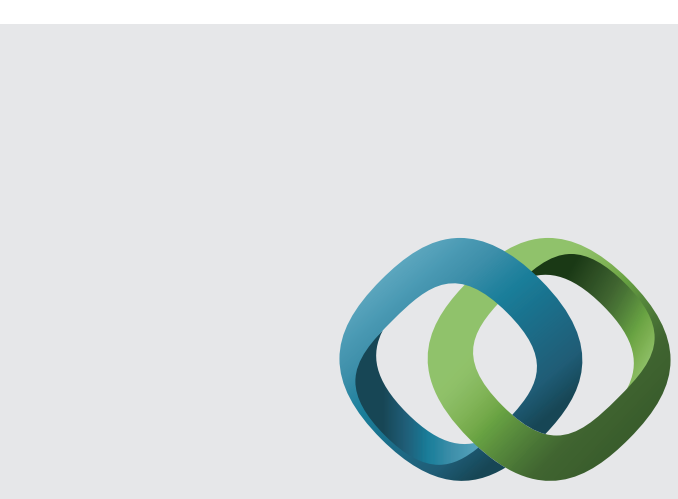

\section{Hindawi}

Submit your manuscripts at

http://www.hindawi.com
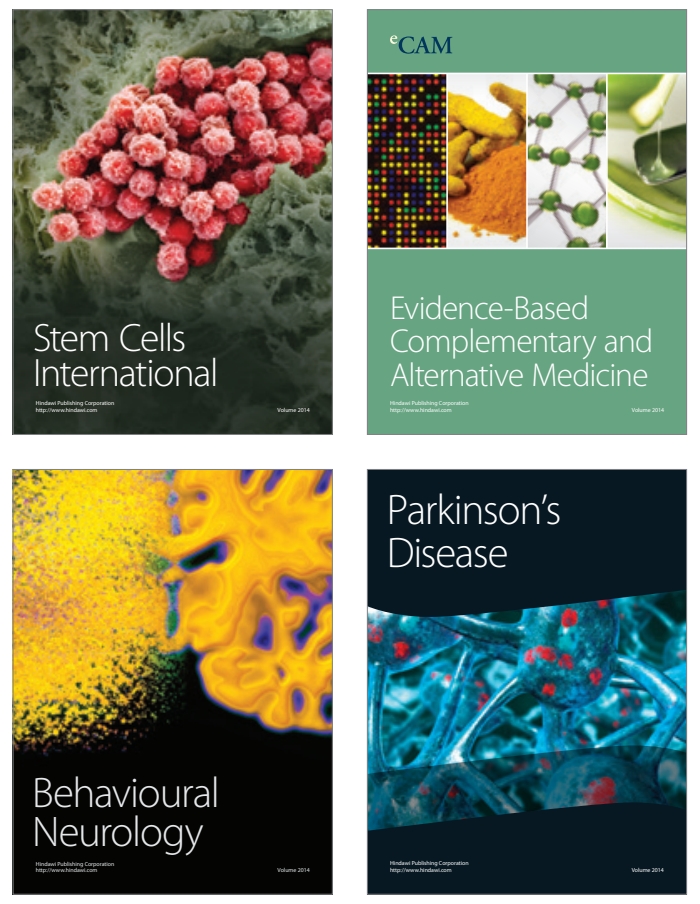
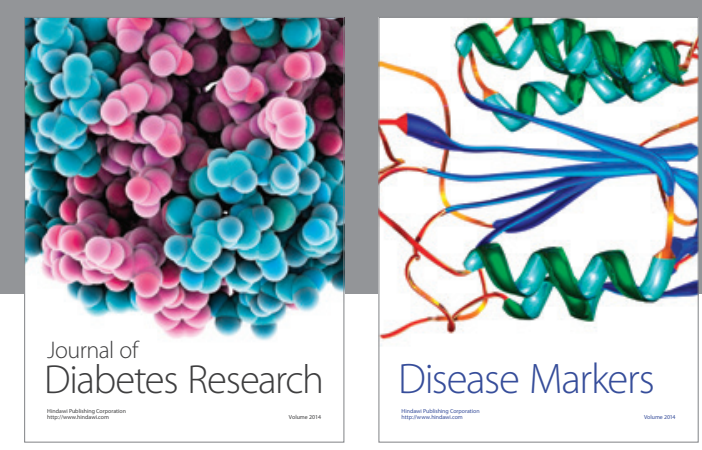

Disease Markers
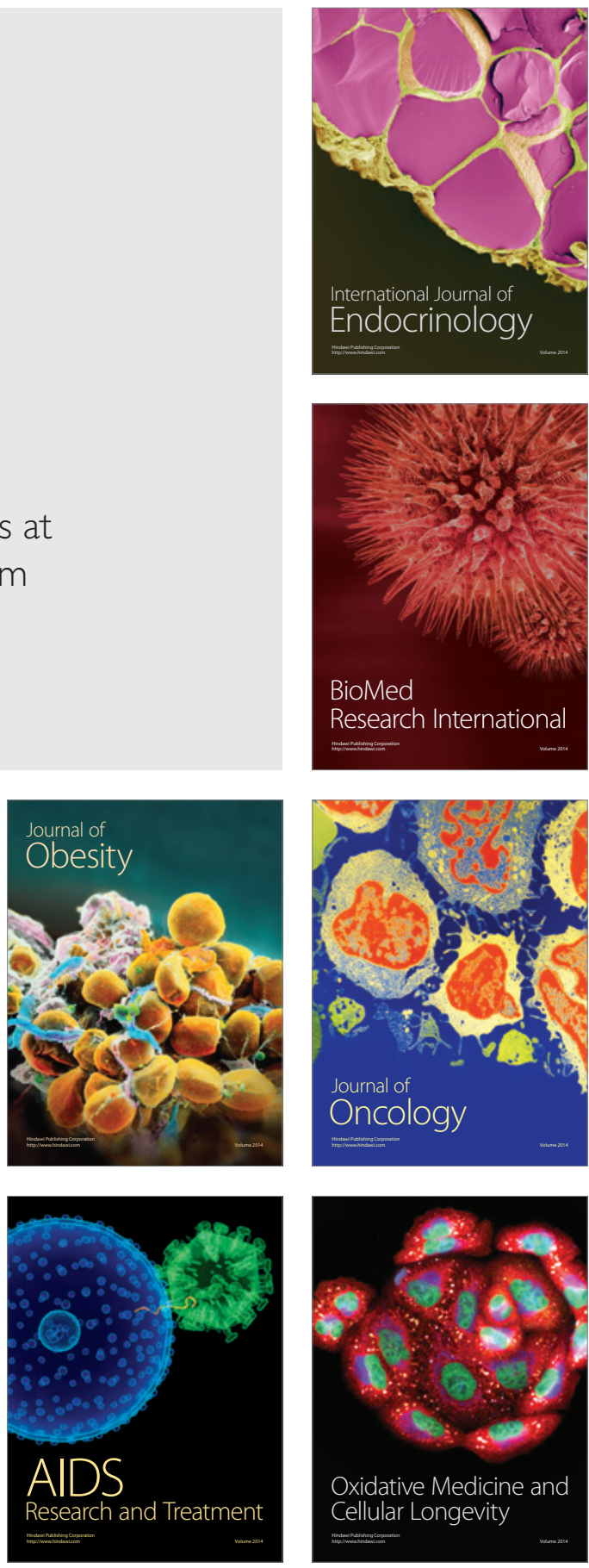